\title{
Os Modelos de Controle para o Crime de Colarinho Branco
}

Luciana Krempell Varela

Resumo: O estudo do crime de colarinho branco (white-collar crime) constitui, sem dúvida, um dos mais interessantes e conflituais capítulos da criminologia contemporânea. A crescente criminalidade econômica no Brasil e no mundo e a sensível impotência dos órgãos, meios e instrumentos estatais, da administração pública encarregados de sua prevenção e repressão, fizeram-nos propor o tema dos modelos de controle para o crime de colarinho branco. Considerando a importância do tema para o Direito Penal Econômico, bem como a preocupação dos legisladores hodiernos para com este tipo de criminalidade, o presente estudo pretende analisar as formas de controle. Salientando, desde já, que tais modelos de controle devem funcionar de maneira transparente e adequada, evitando-se, assim, abusos de poder. Com base nesses também nos é possível estabelecer um posicionamento a respeito da pena cabível, adequada e eficaz ao criminoso de "colarinho branco". Será que a pena privativa de liberdade pode ser dotada de eficácia no delito econômico?

Palavras-chave: Crime de colarinho branco - Crime económico - Criminologia - Modelos de controle - Ressocialização - Pena privativa de liberdade

\section{ABSTRATC \\ Controlling Models of the White Collar Crime}

The study of the White Collar crime constitutes, undoubtedly, one of the most interesting and conflictuous chapters of the contemporary criminology. The growing economic criminality in Brazil and in the world and the considerable impotence of the state organisms, means and instruments of the public administration in charge of its prevention and repression have lead us to propose the topic for the controlling models of the white collar crime. Considering the importance of this topic for the Economic Criminal Law, as well as the preoccupation of the current legislators to this kind of criminality, the present study aims to analyze the forms of control. Emphasizing from now on that such controlling models should work in a transparent and adequate way, thus avoiding abuse of power. Based on that it is also possible to establish a position in respect to the appropriate, adequate and efficacious penalty to the white collar offender. Would the custodial penalty be effective for the economic crime?

Keywords: White collar crime - Economic crime - Criminology - Controlling Models Resocialization - Custodial Penalty 
Sumário: 1. Considerações iniciais - 2.Instâncias formais de controle -3 . Modelo preventivo -4 . Modelo repressivo - 5. Nosso posicionamento - 6. Conclusão - 7 . Bibliografia - 8. Notas de final de texto.

\section{Considerações iniciais}

O Direito Penal é o ramo do Direito que mais sofre diante das modificações políticas pelas quais passa a sociedade, devido a sua maior sensibilidade.

Os crimes de colarinho branco, via de regra, acabam ocasionando reflexos em toda a sociedade, nomeadamente no sistema financeiro. Os denominados delitos financeiros que constituem, em nosso país, um dos crimes que ocasionam os maiores danos para a economia são tratados pelo direito penal econômico. Trata-se, segundo João Marcello de Araújo Júnior, do “(...) ramo do Direito Penal que se destina a sancionar com uma pena as graves violações à "ordem econômica". Em suma, os delitos financeiros se destinam a punir as condutas intoleráveis, que importem em manobras lucrativas em prejuízo geral, mediante o aproveitamento da estrutura e organização do sistema financeiro, no qual se incluem as empresas de capital aberto". ( $\left.{ }^{\mathrm{i}}\right)$

Um dos problemas enfrentados pelo direito penal econômico, em relação aos criminosos de colarinho branco, é que "o próprio juízo da sociedade é de tolerância e de compreensão para a maior parte das violações da vida económica." (ii) Apesar desse quadro estar sofrendo algumas alterações, da sociedade parecer um pouco mais consciente dos problemas ocasionados por tal criminalidade, ainda estamos longe do ideal.

Dessa forma, podemos dizer que o direito penal econômico acaba por exigir, uma vez que se identifica cada vez mais com referida criminalidade, um sistema punitivo próprio. Mas mais do que isso, que seja eficaz. Isso porque, estamos diante de criminosos para os quais sempre esteve presente a idéia do "nothing works", ou seja, de que nunca são punidos e isso não pode continuar na sociedade atual. Prova clara da afirmação feita, ou seja, de que o criminoso de colarinho branco muitas vezes não é punido, pode ser dada através de um caso concreto, ocorrido no Brasil quando da realização, no Congresso Nacional, no ano de 1993, da CPI referente a análise de possíveis falhas no Orçamento da União - CPI do Orçamento. Nessa oportunidade foram 18 os acusados e nenhum condenado à pena de prisão. 
Faz-se necessária, assim, a efetiva punição dos agentes para que seja estancado este tipo de delito e, para tanto, os modelos de controle devem funcionar adequadamente, não abusando do poder que detém. Só assim poderemos vislumbrar alterações positivas no quadro de punições e combate aos crimes envolvendo os poderosos. Não podemos continuar admitindo que em razão de geralmente gozarem de prestígio social, podendo ser encontrados em todas as esferas, nomeadamente nas governamentais, criem um poder paralelo. Os administradores acabam não atuando com a probidade e transparência que lhes seria desejável e acabam facilitando o cometimento de infrações, que acabam gerando consequiências gravíssimas para a sociedade.

Se é certo que, quando estamos diante do criminoso de colarinho branco não podemos imaginar a pena com o fim de ressocialização com o mesmo alcance da criminalidade comum, também não é menos certo que um sistema punitivo eficaz precisa ser garantido, a fim de que as necessidades de prevenção geral e especial sejam cumpridas.

Não nos resta dúvida de que as finalidades das penas, ao contrário do que ocorre em relação à criminalidade comum, na qual além da intimidação, servem de instrumento de reinserção social, apresentam no crime econômico, nomeadamente, a finalidade de retribuir o mal causado e de o prevenir. Acreditamos, inclusive, muito mais nesta última. Evidente que também, em alguns casos, poderá ter um fim ressocializador.

$\mathrm{Na}$ realidade, a prisão não terá, relativamente ao delinqüente econômico, o mesmo efeito criminógeno que possui relativamente ao delinqüente comum: quer porque as técnicas de aprendizagem não podem ser transmitidas ou desenvolvidas na prisão; quer porque não haverá em princípio que recear os efeitos negativos irreversíveis da experiência prisional, que em geral advêm da estigmatização, da distância social, da escassez de oportunidades legítimas, da aquisição de uma identidade e de uma self-image delinqüente, da entrada numa carreira delinqüente. $\left({ }^{\mathrm{iii}}\right.$ )

Pergunta-se, então: “(...) se muito do crime de colarinho branco manifesta um elevado grau de danosidade e se os seus agentes actuam, frequentemente, com culpa grave, não será uma injustiça manifesta não os punirmos «como eles merecem», por contraposição ao que parece suceder com o criminoso comum, muitas vezes menos censurável e gerador de menor desvalor para a comunidade? Como conciliar a realização da justiça, mormente na sua dimensão da igualdade, sem desproteger outros interesses também relevantes da própria sociedade?". ( ${ }^{\mathrm{iv}}$ )

Para responder a esta indagação, faremos uma análise a respeito das instâncias formais de controle do crime, como também os modelos de controle possíveis: o de prevenção e o de 
repressão, mas prevenção não no sentido apresentado pelos fins das penas, não no sentido técnico, mas sim no sentido de evitar o ocasionamento de um mal.

\section{Instâncias formais de controle}

A corrente interacionista salienta que o crime não consiste em uma qualidade da conduta, mas em uma atribuição resultante da interação social. O desvio é considerado como uma construção social, e não como uma realidade existente para além dos indivíduos. $\mathrm{O}$ desvio é, portanto, uma criação da sociedade. $\left(^{\mathrm{v}}\right)$

Frank Tannenbaum foi um dos seus principais precursores durante a década de 70 sendo que, em sua obra Crime and Community, o autor estabeleceu, de forma clara, não apenas o aspecto negativo trazido pela teoria do etiquetamento (labeling approach), como também os principais aspectos conflitivos do processo que ele denominou de dramatização do mal. $\left({ }^{\text {vi }}\right)$ Referida teoria utiliza-se de conceitos como o de "conduta desviada" e "reação social".

Genuinamente norte-americana, surge com a modesta pretensão de oferecer uma explicação científica aos processos de criminalização, às carreiras criminais e à chamada desviação secundária, adquirindo, sem embargo, com o tempo, a natureza de mais um modelo teórico explicativo do comportamento criminal. $\left({ }^{\mathrm{vii}}\right)$

Howard Saúl Becker, por sua vez, também deve ser mencionado ao falarmos da corrente interacionista ( ${ }^{\text {viii }) ~ j a ́ ~ q u e ~ p r o v a v e l m e n t e ~ e ́ ~ o ~ c r i m i n o ́ l o g o ~ i n t e r a c i o n i s t a ~ m a i s ~}$ importante, tendo trazido as maiores contribuições em termos de estudos a respeito da conduta desviada. $\left({ }^{\mathrm{ix}}\right)$ Esclarece em seus estudos as relações de poder presentes por detrás das leis, bem como a sua forma de aplicação. No entanto, devemos ressaltar que não adota um posicionamento determinista, estando distante do positivismo causalista. Considera a conduta humana essencialmente social e, ainda, que a conduta desviante é uma criação da própria sociedade, uma vez que os indivíduos tem a sua conduta assim considerada quando a sociedade assim estabelece. $\left({ }^{x}\right)$ "O desvio não é uma qualidade do autor, mas um processo interativo, no qual conta tanto a conduta referida, como a resposta dos outros." $\left({ }^{\mathrm{xi}}\right)$

Acreditamos, nesse momento, poder entender, com base nesses argumentos trazidos por Becker, o porquê dos criminosos poderosos, em geral, não serem "etiquetados" ou "rotulados" pela sociedade como criminosos. Isso decorre do fato de nem "todos los violadores de normas son vistos como desviantes, y, por otro lado, que no todos los que son vistos como desviantes han cometido actos desviados". ( ${ }^{\text {xii }}$ ) O primeiro caso é nitidamente 
aplicável aos criminosos de colarinho branco que cometem delitos gravíssimos, que acabam afetando, inclusive, as estruturas da sociedade, mas na maioria das vezes não são percebidos por esta. Tudo isso gerando como conseqüências não apenas delitos praticados cujos agentes saem impunes, como também um aumento das cifras negras. Combater essa situação torna-se um verdadeiro desafio à sociedade.

Em consonância com o que estabelece a perspectiva interacionista, segundo Pablos de Molina e Luiz Flávio Gomes, “(...) não se pode compreender o crime prescindindo da própria reação social, do processo social de definição ou seleção de certas pessoas e condutas etiquetadas como delitivas. Delito e reação social são expressões interdependentes, recíprocas e inseparáveis. A desviação não é uma qualidade intrínseca da conduta, senão uma qualidade que lhe é atribuída por meio de complexos processos de interação social, processos estes altamente seletivos e descriminatórios". ( ${ }^{\text {xiii }}$ )

Isto é notado em relação a clara diferença existente em relação ao tratamento dispensado aos white-collar criminals e ao tratamento dispensado aos criminosos comuns.

Assim, a partir do momento que o enfoque da problematização é alterado do que o homem faz e porquê o faz, para a maneira como a sociedade irá reagir ao crime e porquê o faz, o estudo das instâncias de controle acabou sendo convertido em objeto da criminologia. Corroborando tal posicionamento, afirmam Figueiredo Dias e Costa Andrade que tal modificação em relação as instâncias de controle foi "tanto, de resto, das instâncias formais de controlo, situadas dentro do campo restrito de actuação jurídica sobre o crime, como das instâncias informais, isto é, das agências sociais que, não actuando dentro do sistema da justiça penal, condicionam ainda a resposta social ao crime e ao delinquente". $\left({ }^{\text {xiv }}\right.$ ) (grifo dos autores)

As denominadas instâncias formais de controle incluem desde a lei (como instância de criminalização primária), até a efetiva aplicação da sanção estabelecida na sentença, ou seja, até a execução. Isso quer dizer que "desde el momento de creación de la ley, hasta el de su aplicación a determinadas personas, por obra de la policía, los tribunales y la administración penitenciaria, se va operando un proceso, según esta corriente, que culmina con el etiquetamiento de un individuo como criminal". $\left({ }^{\mathrm{xv}}\right)$

O que implica iniciarmos pela lei criminal para, então, podermos vislumbrar a sistemática da reação criminal, especialmente, no que diz respeito aos criminosos de colarinho branco, já que sabemos que uma coisa é o cometimento de uma infração penal e outra bem diferente é o indivíduo vir a ser acusado e, ainda, condenado por tal delito. 
Em razão do fato de ser transparente a imensa defasagem existente entre a previsão abstrata feita pela lei criminal e a efetiva punição definitiva, efetuada pelas instâncias de criminalização secundária, cabe-nos “(...) acompanhar a trajectória da law in action e da law in force, para atestar a sua (in)capacidade real de atingir os comportamentos subsumíveis nas suas previsões abstractas e de resistir às subculturas informais e aos second-codes que presidem às instâncias de criminalização secundária". ( ${ }^{\mathrm{xvi}}$ ) (grifo dos autores)

Uma clara demonstração do que vem sendo afirmado aparece através das cifras negras que são originadas em todas as fases do processo formal de reação ao comportamento delinqüente. Em face dessa seleção de cunho quantitativo é que se acaba demonstrando a ocorrência do "efeito funil" e da "mortalidade dos casos criminais". $\left({ }^{x v i i}\right)$

Assim, o fato de uma parte dos delitos praticados acabarem se perdendo durante as várias instâncias de controle, implica uma diminuição muito grande em termos de punição se compararmos com o número de casos que iniciam a investigação. Essa seleção acaba, na maioria das vezes, gerando conseqüências negativas no seio da sociedade, principalmente no que diz respeito à segurança jurídica e à efetividade de aplicação da lei penal aos casos concretos.

A grande discricionariedade que acaba sendo utilizada pelas instâncias de controle pode ser prejudicial para o andamento da justiça penal como um todo, já que, segundo Miguel Langon Cuñarro, “(...) puede llevar a graves distorsiones en orden a la selectividad de su tarea. Son los policías los primeros en decidir, en los hechos, qué delitos se investigarán y cuáles no, a qué personas se detendrá y a cuáles no, en definitiva, qué normas, de las tantas que existen en el catálogo de la ley, serán hechas realidad a través de su actuación”. ( ${ }^{\text {xviii }}$ )

Com efeito, essa nítida seleção em relação à delinqüência é um grande problema que tem reflexos em cifras negras regulares em relação aos criminosos poderosos, num evidente “predomínio desproporcionado das classes inferiores nas instâncias de controlo e nas estatísticas oficiais da criminalidade, não podendo imputar-se ao caso, antes devem encarar-se como grandezas sistematicamente produzidas." ( ${ }^{\mathrm{xix}}$ ) O que implica dizer que estamos diante de uma desigualdade de tratamento por parte das instâncias de controle que, mais uma vez, vem a favorecer os criminosos poderosos, diminuindo a competência de ação das classes menos favorecidas, devido a sua menor capacidade de influência, em face da sua situação econômico-social menos favorável.

Dessa forma, acaba havendo um necessário efeito seletivo em relação aos agentes dos delitos antieconômicos, pelas instâncias de controle e “(...) as malhas do direito penal, neste domínio, vêm a apanhar tão-só alguns dos seus infractores, deixando, aqui, mais do que em 
qualquer outro ramo, esconder nas cifras negras a maioria dos responsáveis por comportamentos antieconómicos”. $\left({ }^{\mathrm{xx}}\right)$

Portanto, “(...) a «competência de acção», sendo, em geral, mediatizada pelos processos sociais, é diferencialmente distribuída. Uma vez que os códigos de comunicação no processo criminal seguem privilegiadamente os modelos dos adultos da classe média, são sobretudo os jovens e os membros das classes inferiores que surgem, em princípio, mais carecidos da competência de acção específica do processo penal. É, por isso, natural que sobre eles impendam maiores probabilidades de criminalização". ( ${ }^{\mathrm{xxi}}$ ) (grifo dos autores)

Definitivamente, não podemos aceitar que tal quadro continue na aplicação da justiça penal. Mudanças devem ser propostas. Respostas devem ser trazidas a todos esses problemas para que a sociedade chegue a um melhor equilíbrio.

Diante desse quadro de pequena influência, é possível inferir como conseqüência uma menor resistência por parte dessas pessoas perante o processo, o que implicará em mais um ponto de desigualdade.

Evidentemente que, quando falamos na necessidade de melhorias em relação a tal seleção, não estamos cogitando da possibilidade de termos uma absoluta relação entre o que se está investigando e os casos que são efetivamente apurados. A aplicação total e sem lacunas da lei seria absolutamente impossível até em termos de normal funcionamento da vida social. Acreditamos que deva ser buscado um certo equilíbrio entre o que se investiga e o que se pune.

É importante que salientemos, no entanto, que tudo o que mencionamos, até então, está dizendo respeito apenas às instâncias formais de controle, já que não entraremos no mérito específico dos impactos causados na seleção que ocorre nas instâncias informais de controle nas quais podemos incluir "desde a difusa tolerância social perante certas formas de criminalidade, às formas mais organizadas de reacção, como a que resulta da «justiça» informal exercida por associações, lojas, empresas, escolas, igrejas, etc". ( ${ }^{\mathrm{xxii}}$ )

Vislumbramos, com tais considerações, deixar claro que ao analisarmos os modelos possíveis de controle em relação aos criminosos de colarinho branco, buscamos registrar a necessidade das instâncias formais de controle atuarem de forma conjunta, coordenada. O que implica não apenas haver comunicação entre as diversas instâncias de controle, como também uma adequada troca de informações entre elas, para que se alcance um padrão de atuação. Com efeito, os padrões de orientação, de gestão seja da atuação na fase de inquérito por parte da Polícia, seja dos membros do Ministério Público e da Magistratura durante a fase processual devem guardar uma certa homogeneidade para que não ocasionem conseqüências 
negativas no seio do sistema da justiça penal. Só assim obteremos êxito, em termos de prevenção do crime, e em termos de seu efetivo controle.

Nesse sentido, afirmam Figueiredo Dias e Costa Andrade que “(...) o estudo das instâncias formais de controlo não pode bastar-se com considerá-las como agências isoladas umas das outras, auto-suficientes e auto-reguladas: uma tal consideração impediria, na verdade, o progresso na área da prevenção e do controlo do crime. Importa, diferentemente, complementar uma tal consideração isolada por um estudo compreensivo e integrado do processo de aplicação da justiça penal, que permita dar uma maior consistência e uma maior eficiência - tal como elas devem ser medidas à luz dos principais objectivos ou metas sistémicas - ao «sistema» como um todo". $\left({ }^{\text {xxiii }}\right.$ )

\section{Modelo preventivo}

A filosofia prevencionista, nos últimos anos, vem ganhando cada vez maior destaque e a Criminologia nesse contexto exerce um papel fundamental, incluindo o estudo das variáveis do delito, que acaba por gerar grandes possibilidades para que uma prevenção eficaz seja efetivada.

De fato, "a Criminologia como ciência interdisciplinar, trata de identificar aquelas variáveis, explicando de que forma interatuam e como configuram dinamicamente o muito complexo e seletivo fato delito. Por isso, o progresso criminológico enriquece nossos conhecimentos sobre o delito e sugere novas estratégias de prevenção cada vez mais ambiciosas, ampliando inclusive o círculo de destinatários naturais (infrator potencial ou o condenado) de tal intervenção, para alcançar outros protagonistas do fenômeno delitivo (v.g., a vítima), assim como dados, fatores ou elementos que convergem de modo decisivo para esse acontecimento criminal (v.g., espaço físico, desenho arquitetônico, habitat urbano, clima social etc)". ( ${ }^{\text {xxiv }}$ )

O que devemos ter sempre cristalino em relação à prevenção é que ela é sempre uma boa solução, ou seja, é melhor prevenir um mal do que depois ser necessário punir a sua efetivação. Em relação ao crime de colarinho branco, ainda faz mais sentido tal afirmação, uma vez que diante desta criminalidade, estamos perante a possibilidade de inúmeras pessoas serem afetadas pela prática do delito, como é o caso do crime contra o meio ambiente, o crime contra os consumidores, etc, em relação aos quais muitas vezes o prejuízo é irrecuperável; além disso, considerando que a eficácia da punição em relação a tais criminosos é muitas vezes comprometida, o melhor mesmo é prevení-los; e, por fim, "sendo o agente de colarinho 
branco alguém que atuará, regra geral, no quadro de escolhas racionais, tornar-se-á mais fácil a prevenção situacional." ( ${ }^{\mathrm{xxv}}$ )

Portanto, "a necessidade de um tratamento sério e amplo de tais delitos é manifesta, especialmente se atentarmos para o fato de que o nosso Direito Penal dispõe de escassas e, lamentavelmente, imperfeitas normas, numa legislação fragmentária, elitista e seletiva, que tem como consequiência, a impunidade". $\left({ }^{\mathrm{xxvi}}\right)$

No entanto, se é certo que a prevenção parece uma boa solução, ainda não se têm clara qual é a melhor forma de efetivá-la. Propostas são apresentadas, mas na realidade o que se faz necessária é a sua implementação de maneira eficaz, com o intuito de realmente prevenir a sociedade contra os riscos e conseqüências do crime de colarinho branco.

Cláudia Santos nos deixa bem transparente esta idéia, em relação as propostas que têm sido apresentadas, afirmando a preocupação de alguns autores em buscar soluções para as insuficiências existentes em relação a esse tipo de criminalidade dentro de uma linha clássica repressiva, mesmo diante de uma literatura escassa sobre o assunto.

Segundo a autora, "Stone, por exemplo, advogou a adopção de medidas intrusivas na própria estrutura da organização com o intuito de condicionar o processo de decisão, e salientou a importância da existência de um sistema informativo que desenvolva ao possível agente da infracção o feedback dos receios associados à sua conduta. Entre outros aspectos, defendeu a obrigatoriedade de registros no seio da organização quando estejam em causa decisões ou actividades de risco; a responsabilização daqueles que ocupam os postos mais importantes impondo-se que eles tenham conhecimento do que se passa nos seus sectores; a obrigatoriedade de os centros de decisão terem lugares ocupados por representantes dos consumidores, dos trabalhadores e/ou das entidades responsáveis pela fiscalização da qualidade dos produtos ou do respeito pelas normas de segurança... Por outro lado, vários autores têm destacado a importância da tecnologia como forma de prevenir o crime de colarinho branco - se ela é utilizada, frequentemente, para o perpetrar, o seu domínio constitui um elemento chave na detecção e controlo destas infracções. Paralelamente, tem sido salientado o domínio da auto-regulamentação como forma de garantir o cumprimento das normas no seio da organização ou da actuação do profissional liberal, o que surge também como uma forma de prevenir infracções que é prévia ao sancionamento penal". $\left({ }^{\mathrm{xxvii}}\right)$

No entanto, "a auto-regulamentação, não obstante as vantagens que apresenta, dificilmente se poderá, porém, substituir ao controlo estadual." ( ${ }^{\text {xxviii }}$ )

E, ainda em relação a prevenção, estabelece que há mais um aspecto que deve ser considerado importante, que é a previsão de limites máximos em relação as sanções 
pecuniárias, a fim de evitar a realização de cálculos pelos criminosos no sentido de que o cometimento do crime compensa se for comparado ao montante em dinheiro que lhe será cobrado em uma eventual condenação. Isso porque, em sendo possível esse cálculo por parte dos criminosos, poderão agir baseados em números que os façam acreditar que o lucro advindo da infração é maior que um eventual pagamento de uma multa. O seu poder econômico acaba por amortizar o efeito da multa. Além disso, tal multa nem sempre é aplicada, uma vez que estamos diante de uma criminalidade que muitas vezes escapa das instâncias de controle e acaba ficando impune.

Isso definitivamente não pode ser uma possibilidade aos white-collar criminals, já que não podemos nos esquecer que as conseqüências de cunho econômico são muito maiores do que os números por eles calculados, em razão do fato de atingirem a sociedade como um todo. "A criminalidade económica é uma ameaça séria a minar os alicerces de qualquer sociedade organizada." $\left({ }^{\mathrm{xxix}}\right.$ )

\section{Modelo repressivo}

Além do modelo preventivo, o qual já fizemos menção à sua importância, não podemos deixar de tecer algumas considerações sobre o modelo repressivo.

É sabido que, em relação à criminalidade de colarinho branco, as cifras negras são muito altas, haja vista não apenas o grande número de agentes que não são punidos, como também o número de delitos desta espécie que nem ao menos chegam a ser computados nas estatísticas criminais, por não chegarem ao conhecimento dos órgãos de controle. Realmente, "o crimeconhecido-pela-polícia constitui o limiar da criminalidade oficial e estatística" ( ${ }^{\mathrm{xxx}}$ ) e tal entidade acaba por exercer um papel fundamental no desempenho do combate à criminalidade, especialmente em relação a criminosos como os de colarinho branco, cujas vítimas acabam sendo abstratas e para os quais é necessária uma perfeita interatividade entre a polícia e aquele que irá fazer a denúncia do delito para que, então, seja logrado êxito na apuração da infração penal.

Duas perguntas que se colocam são as seguintes: podemos considerar razoável que assim seja, tendo em vista que tal tipo de criminalidade geralmente não necessita de uma ressocialização por parte dos seus agentes? Ou será que, através destes pensamentos, estaremos apresentando um comportamento desigual que não pode ser aceito pela justiça penal? 
Em primeiro lugar, devemos esclarecer que nem todos os crimes de colarinho branco apresentam a mesma gravidade, de tal forma que este aspecto é a primeira coisa que deve ser levada em consideração. Com efeito, “(...) alguns white-collar adoptam condutas que a comunidade não vê como particularmente desvaliosas e não estão carecidos de ressocialização. Das infracções que aqui englobamos, umas não deveriam ser sequer objecto de criminalização, enquanto outras, atentas as especificidades da situação concreta, não carecem da aplicação de um pena de prisão. Mas muitas outras, pelo desvalor que representam, pela danosidade que lhes subjaz, não podem ser exteriores à repressão penal, sob pena de se introduzir uma antinomia gravemente desigualitária no sistema: referimo-nos sobretudo àquelas condutas em que dolosamente ou com negligência grave se põe em perigo a vida ou a integridade física das pessoas". ${ }^{\text {xxxi }}$ )

Portanto, para evitar qualquer tipo de tratamento desigualitário, o que convém é aplicar aos casos nos quais a perigosidade para a sociedade é menor, o direito penal mínimo, sempre considerando os princípios da necessidade e proporcionalidade, ao passo que, nos casos que englobam as segundas condutas, por nós supra mencionadas, é necessário que o sistema puna de maneira mais severa, não podendo o poderio dos seus agentes influenciar o funcionamento das instâncias de controle.

Se estamos diante de um crime, com certa gravidade, há de ser aplicada uma punição adequada. Não significando, com isso, que sempre esta punição deva implicar na aplicação sistemática de uma pena privativa de liberdade.

Corroborando o nosso entendimento, Cláudia Santos estabelece que "quanto ao julgamento e à determinação da sanção criminal, o que defendemos não é que os criminosos de colarinho branco sejam sistematicamente condenados a penas de prisão efectivas. Seria, de facto, uma enorme contradição apontar as desvantagens da pena privativa da liberdade em relação ao grosso da criminalidade - mencionando o seu carácter dessocializador, estigmatizante e criminógeno - e vir depois clamar pela sua aplicação em maior número de casos aos white-collars. O que nos parece imperativo é, ao invés, que, tal como em relação a todos os agentes considerados culpados pela prática de um crime, a pena de prisão só seja aplicada quando for indispensável à luz de considerações preventivas”. ( ${ }^{\text {xxii }}$ (grifo da autora)

\section{Nosso posicionamento}

As possíveis soluções apresentadas em relação a quais sanções são cabíveis e eficazes em relação a criminalidade de colarinho branco são muitas, $\left({ }^{\text {xxxiii }}\right)$ mas sempre ressaltando que um importante ponto de partida a ser levado em consideração é em relação tanto à 
profissionalização, como à burocratização vivida no seio do sistema de reação ao crime. A verdade é que "as estruturas tradicionais de aplicação do direito não resistiram à avalanche da massificação da criminalidade." ( ${ }^{\text {xxxiv }}$ )

Como conseqüência, tanto dessa profissionalização como da burocratização do sistema formal de controle, inseridos em uma sociedade na qual cada vez menos as pessoas são identificadas, as instâncias formais de controle passaram a trabalhar, basicamente, com os dados constantes dos autos, como verdadeiros standarts, modelos a serem seguidos. E, ainda, “(...) as decisões são não só determinadas pelo sentido normativo das leis a aplicar, mas também - e, quantas vezes, principalmente - pré-determinadas por ideologias (no seu mais amplo sentido) interiorizadas por indivíduos que, em primeira linha, prosseguem o sucesso profissional". $\left({ }^{\mathrm{xxxv}}\right)$

\section{CONCLUSÃO}

Dessa forma, após a análise dos modelos preventivo e repressivo, concluímos também que o Estado de Direito não pode abdicar de tais modelos, sob pena de estar abandonando a sua função. Isso porque, independentemente do modelo que será adotado diante de uma certa criminalidade, o fato é que algum deverá de o ser, não apenas pelo fato de ser indispensável à tutela da segurança, como também pelo papel fundamental que exerce em relação aos direitos e liberdades dos cidadãos.

No entanto, no nosso entender, em que pese a lógica e coerência dos argumentos apresentados por diversos doutrinadores, posicionamos-nos no sentido de que, em muitos casos, a pena privativa de liberdade é necessária e eficaz para combater a criminalidade de colarinho branco. Isso porque, se a maioria dos argumentos contrários à aplicação de tal modalidade de pena aos crimes de colarinho branco é no sentido de que tal medida é desnecessária em razão da sua inadequação, dos crimes geralmente não serem violentos e, ainda, pelo fato da prisão ostentar caráter ressocializador, não necessário a este tipo de agentes, não podemos com isso afirmar que o encarceramento se torna menos necessário em algumas situações. ${ }^{\mathrm{xxxvi}}$ )

Além disso, devemos estar conscientes que os criminosos de colarinho branco, na sua grande maioria, são reincidentes e tem a prática criminosa inserida nos seus atos cotidianos,

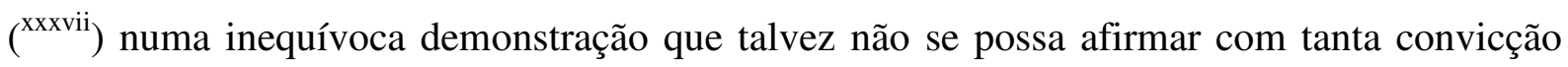
assim, que se tratam de agentes que estão perfeitamente ressocializados. 
Os criminosos de colarinho branco devem receber a aplicação da pena de prisão e não apenas a pena de multa, uma vez que esta última, muitas vezes, não é suficiente para impedir que deixem de delinqüir, podendo ser uma grande fonte de injustiça.

Nesse sentido, lecionam Faria Costa e Costa Andrade:

"Para além de inadequada às exigências de prevenção, a multa pode produzir e potenciar as fontes da injustiça. $\mathrm{Na}$ verdade, dificilmente a multa poderá desincentivar delinquentes economicamente dotados. Acresce que a racionalidade do mundo dos negócios, facilmente permitirá integrar o risco da multa nos «custos» da empresa, estimulando formas de compensação fazendo-a, por exemplo, repercutir sobre operadores económicos situados a juzante, em última análise, os consumidores desorganizados". ( ${ }^{\mathrm{xxxviii}}$ ) (grifo dos autores)

É evidente que o insucesso, tanto no campo da prevenção como no da repressão deste tipo de criminalidade, não pode ser atribuído apenas a uma causa. Mas uma coisa é certa: entendemos que penas mais severas devem ser aplicadas, sobretudo de prisão.

Já que a advertência aos criminosos de colarinho branco a uma possível sujeição as instâncias de controle pode se mostrar insuficiente para os conter, parece-nos que estamos diante da necessidade de aplicação de sanções que incluam as privativas de liberdade. Ainda que sejam penas curtas (sharp-short-shock), $\left({ }^{\mathrm{xxxix}}\right)$ já que diante do perfil de tais criminosos, parece-nos que estas são as penas de prisão mais adequadas, já que podem vir a funcionar sem que apresentem o efeito criminógeno.

Portanto, podemos concluir que não apenas as instâncias formais de controle como os modelos - preventivo ou repressivo - visam, em última análise, a realização, a efetivação da justiça penal. Mas para que isso seja alcançado, providências devem ser tomadas, alternativas devem ser buscadas, nomeadamente quando estamos diante de uma criminalidade com características diversas da chamada de criminalidade clássica e que, dessa forma, merece respostas específicas e que considerem as peculiaridades que lhe são inerentes. É claro que os modelos preventivos ou repressivos possuem falhas que são decorrência de inúmeros fatores concorrentes entre si, mas elas não devem ser suficientes para que não se busquem soluções para tais problemas.

No sentido dos problemas serem diversos podemos exemplificar através de uma análise ao nível das denominadas "seleção primária”, "seleção secundária”, considerações vitimológicas e da opinião pública.

Com efeito, "assim, desde logo, ao nível da chamada "selecção primária" (nível legislativo) assiste-se a uma acrescida dificuldade da definição da arquitectura dos tipos quer devido ao facto de se estar perante bens jurídicos supra-individuais que por, muitas vezes, a 
matéria das condutas proibidas ser rapidamente ultrapassada pela acrescida dinâmica da vida económica e, por outro lado, as sanções cominadas para os respectivos delitos serem, em geral, mais brandas do que as previstas para o direito penal clássico, o que se justificará, em parte, por uma certa "identificação", ao nível do "status social", entre o legislador e o potencial agente de tais ilícitos ou até pela subsistência de uma certa ideia de que a cominação de penas muito severas nesta área constituiria um entrave ao desenvolvimento económico; por seu turno, ao nível da "selecção secundária" (Polícia, Ministério Público e Tribunais) a elevada condição social do delinquente favorece uma atitude de relativa indulgência que, conjugada com a complexidade das matérias a julgar e o poder e influência do típico agente destas formas de criminalidade, concorrem para uma alta taxa de absolvições; também ao nível das considerações vitimológicas as coisas não melhoram, quer porque em geral a vítima estará mais interessada em uma reparação pecuniária do que na perseguição criminal, quer porque, amiúde, está implicada ela própria no crime e por isso não está motivada a participálo, quer, enfim, porque nem sempre terá consciência da sua condição de vítima, justamente devido ao fraco crime appeal destes comportamentos; por fim, também ao nível da opinião pública assiste-se a uma atitude genérica de tolerância e passividade perante tais comportamentos delituosos, encarados por muitos como meros "delitos de cavalheiros". $\left({ }^{\mathrm{xl}}\right)$

\section{REFERÊNCIAS BIBLIOGRÁFICAS}

ALBERGARIA, Pedro Soares de. "A posição de garante dos dirigentes no âmbito da criminalidade de empresa”, Revista Portuguesa de Ciência Criminal, ano 9, fasc. 4, out.-dez. 1999, pp. 605-626.

ARAÚJO JÚNIOR, João Marcelo. "Os crimes contra o sistema financeiro no esboço de nova parte especial do código penal de 1994”, Revista Brasileira de Ciências Criminais, São Paulo: Revista dos Tribunais, ano 3, nº 11, jul./set. 1995, pp. 145-165.

BARATTA, Alessandro. Criminologia Crítica e Crítica do Direito Penal - introdução à sociologia do direito penal (trad. Juarez Cirino dos Santos), Rio de Janeiro: Editora Revan, 3. ed., pp. 85-116.

BECCARIA, Cesare. Dos Delitos e das Penas (trad. J. Cretella Jr. e Agnes Cretella), São Paulo: Revista dos Tribunais, 1996.

BITENCOURT, Cezar Roberto. "Princípios garantistas e a delinquiência do colarinho branco", Revista Brasileira de Ciências Criminais, ano 3, n. 11, jul.-set./1995, pp. 118-127. 
CORREIA, Eduardo. "Introdução ao Direito Penal Económico", Direito Penal Económico e Europeu: textos doutrinários, vol. I, Coimbra: Coimbra Editora, 1998, pp. 293-318.

COSTA, José de Faria e ANDRADE, Manuel da Costa, "Sobre a concepção e os princípios do direito penal económico - notas a propósito do colóquio preparatório da AIDP”, Direito Penal Económico e Europeu: textos doutrinários, vol. I, Problemas Gerais, Coimbra: Coimbra Editora, 1998, pp. 347-364.

COSTA JUNIOR, Paulo José da, QUEIJO, M. Elisabeth e MACHADO, Charles M. Crimes do Colarinho Branco, São Paulo: Saraiva, 2. Ed. 2002.

DIAS, Jorge de Figueiredo. "Breves considerações sobre o fundamento, o sentido e a aplicação das penas em direito penal económico", Direito Penal Económico e Europeu: textos doutrinários, vol. I, Coimbra: Coimbra Editora, 1998, pp. 375-386.

DIAS, Jorge de Figueiredo e ANDRADE, Manuel da Costa. Criminologia - o homem delinquente e a sociedade criminógena, Coimbra: Coimbra Editora, 2a reimpressão, 1997, pp. 130-143; 409-416; 434-441; 447-454 e 527-555.

. "Problemática geral das infracções contra a economia nacional", Direito Penal Económico e Europeu: textos doutrinários, vol. I, Coimbra: Coimbra Editora, 1998, pp. 319346.

D`URSO, Luíz Flávio Borges (coordenador). Justiça Criminal e Sociedade - $3^{o}$ Encontro Nacional dos Advogados Criminalistas, São Paulo: Editora Juarez de Oliveira, 2000, pp. 105121.

FELDENS, Luciano. Tutela Penal de Interesses Difusos e Crimes do Colarinho Branco, Porto Alegre: Livraria do Advogado Editora, 2002, pp. 113-238.

FERNANDES, Newton e FERNANDES, Valter. Criminologia Integrada, São Paulo: Revista dos Tribunais, 2. ed., 2002, pp. 380-509.

FRANCO, Alberto Silva. "Globalização e Criminalidade dos Criminosos", Temas de Direito Penal Econômico, São Paulo: Editora Revista dos Tribunais, 2001, pp. 235-277.

HASSEMER, Winfried e MUÑOZ CONDE, Francisco. Introducción a la Criminología y al Derecho Penal, Valencia: Editorial Tirant Lo Blanch.

MOLINA, Antonio García-Pablos de e GOMES, Luiz Flávio. Criminologia, São Paulo: Revista dos Tribunais, 4. ed., 2002, pp. 372-389.

MOLINA, Antonio Garcia-Pablos de. Problemas actuales de la criminología, Publicaciones del Instituto de Criminología de la Universidad Complutense de Madrid, 1984, pp. 150 e ss. MUÑOZ CONDE, Francisco. "Cuestiones dogmáticas básicas en los delitos económicos”, Revista Penal, año 1, n. 1. 
NUÑEZ FERNÁNDEZ, José. “Algunos aspectos conceptuales y políticos de la criminalidad de cuello blanco", Cuadernos de Política Criminal - Universidad Complutense de Madrid, n. 71, 2000, pp. 523-535.

RODRIGUES, Anabela Miranda. "Contributo para a fundamentação de um discurso punitivo em matéria fiscal penal”, Direito Penal Económico e Europeu: textos doutrinários. Coimbra: Coimbra Editora, v. II - problemas especiais, 1999, pp. 481-489.

RODRIGUEZ MOURULLO, Gonzalo. “Algunas consideraciones político-criminales sobre los delitos societarios", Anuario de Derecho Penal y Ciencias Penales, tomo XXXVII, fasc. III, sep.-dic. 1984, pp. 677-691.

SANTOS, António Almeida. "Novo mundo, novo crime, nova política criminal”, Revista Portuguesa de Ciência Criminal, ano 10, fasc. 3, jul.-set./2000, pp. 351-370.

SANTOS, Cláudia Maria Cruz. "O Crime de Colarinho Branco (da origem do conceito e sua relevância criminológica à questão da desigualdade na administração da Justiça penal)", Stvdia Ivridica 56, Boletim da Faculdade de Direito da Universidade de Coimbra: Coimbra Editora, 2001.

- "O crime de colarinho branco, a (des)igualdade e o problema dos modelos de controlo", Temas de Direito Penal Econômico, São Paulo: Editora Revista dos Tribunais, 2001, pp. 192-222.

SANTOS, Weliton Militão dos. "Lei 7.492/86; os artigos 30 e 31 da Lei 7.492/86 e o princípio inocência; confronto com artigo 312 do CPP”, Revista da Associação dos Juízes Federais do Brasil - AJUFE, ano 18, n. 60, janeiro-março 1999, pp. 81-118.

SUTHERLAND, Edwin H.. White-collar Crimes - the uncut version, New York: Vail-Ballou Press, 1983, pp. 3-10 e 240-257.

TORON, Alberto Zacharias. "Crimes de colarinho branco: os novos perseguidos?”, Revista Brasileira de Ciências Criminais, ano 7, n. 28, out.-dez./1999, pp. 73-84.

- "Notas sobre a mídia nos crimes de colarinho branco e o judiciário: os novos padrões", Revista Brasileira de Ciências Criminais, ano 9, n. 36, out.-dez./2001, pp. 257-272. VIRGOLINI, Júlio E. S. "Delito de cuello blanco. Punto de inflexión en la teoría criminológica”, Doctrina Penal - Teoría y Práctica en las Ciencias Penales, año 12, n. 46/47, abr.-sep./1989, pp. 353-367.

e GARCIA LOREA, Carlos A. "La ley penal tributaria", Doctrina Penal - Teoría y Práctica en las Ciencias Penales, año 13, ns. 49 a 52, 1990, pp. 455-468.

WHEELER, Stanton; MANN, Kenneth e SARAT, Austin. Sitting in Judgment - the sentencing of White-Collar Criminals, Yale University Press, 1988. 
WEISBURD, David; CHAYET, Ellen F. E WARING, Elin J. "White-Collar Crime and Criminal Careers: Some Preliminary Findings", Crime \& Delinquency, vol. 36, n. 3, July 1990, pp. 342-355.

\section{NOTAS DE FINAL DE TEXTO}

\footnotetext{
${ }^{\mathrm{i}}$ Os crimes contra o sistema financeiro no esboço de nova parte especial do código penal de 1994. Revista Brasileira de Ciências Criminais, São Paulo: Revista dos Tribunais, ano 3, nº 11, jul./set. 1995, p. 148.

ii CORREIA, Eduardo. Introdução ao Direito Penal Económico. Direito Penal Económico e Europeu: textos doutrinários, v. I, p. 297.

iii DIAS, Jorge de Figueiredo. Breves considerações sobre o fundamento, o sentido e a aplicação das penas em direito penal económico. Direito Penal Económico e Europeu: textos doutrinários, v. I, p. 383.

${ }^{\text {iv }}$ SANTOS, Cláudia Cruz. O crime de colarinho branco, a (des)igualdade e o problema dos modelos de controlo. Temas de Direito Penal Econômico, p. 209.

${ }^{\vee}$ Especificamente sobre os aspectos gerais apresentados pelo interacionismo em criminologia, vide LANGON CUNARRO, Miguel. Criminologia sociológica, p. 14 e ss.

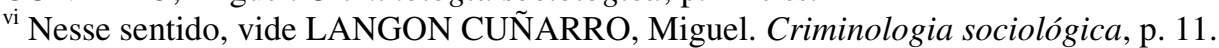

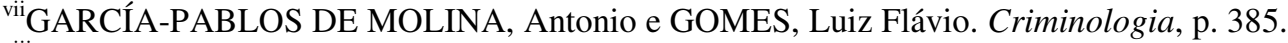

viii Sobre a Escola Interacionista, ANIYAR DE CASTRO, Lola. Criminalidade da reação social, p. 96 e ss.

${ }^{\text {ix }}$ Sobre o assunto, vide ANIYAR DE CASTRO, Lola. Criminalidade da reação social, p. 88-91.

${ }^{x}$ Nesse sentido, vide LANGON CUÑARRO, Miguel. Criminologia sociológica, p. 27 e ss.

${ }^{x i}$ ANIYAR DE CASTRO, Lola. Criminalidade da reação social, p. 88.

xii LANGON CUÑARRO, Miguel. Criminologia sociológica, p. 28.

xiii GARCÍA-PABLOS DE MOLINA, Antonio e GOMES, Luiz Flávio. Criminologia, p. 385.

${ }^{x i v}$ DIAS, Jorge de Figueiredo e ANDRADE, Manuel da Costa. Criminologia - o homem

delinquente e a sociedade criminógena, p. 365.

${ }^{\mathrm{xv}}$ LANGON CUÑARRO, Miguel. Criminologia sociológica, p. 14.

${ }_{x v i}$ DIAS, Jorge de Figueiredo e ANDRADE, Manuel da Costa. Criminologia - o homem delinquente e a sociedade criminógena, p. 366-367.

xvii Corroborando o nosso entendimento, DIAS, Jorge de Figueiredo e ANDRADE, Manuel da Costa. Criminologia - o homem delinquente e a sociedade criminógena, p. 367.

xviii Criminologia sociológica, p. 30.

xix DIAS, Jorge de Figueiredo e ANDRADE, Manuel da Costa. Criminologia - o homem delinquente e a sociedade criminógena, p. 385.

${ }^{x x}$ CORREIA, Eduardo. Introdução ao direito penal económico, Direito Penal Económico e Europeu: textos doutrinários, v. I, p. 300.

${ }^{x x i}$ DIAS, Jorge de Figueiredo e ANDRADE, Manuel da Costa. Criminologia - o homem delinquente e a sociedade criminógena, p. 385.

xxii DIAS, Jorge de Figueiredo e ANDRADE, Manuel da Costa. Criminologia - o homem delinquente e a sociedade criminógena, p. 372.

xxiii DIAS, Jorge de Figueiredo e ANDRADE, Manuel da Costa. Criminologia - o homem delinquente $e$ a sociedade criminógena, p. 374.

${ }^{\text {xxiv }}$ GARCÍA-PABLOS DE MOLINA, Antonio e GOMES, Luis Flávio. Criminologia, p. 435.

${ }^{x x v}$ SANTOS, Cláudia Cruz. O crime de colarinho branco, a (des)igualdade e o problema dos modelos de controlo. Temas de Direito Penal Econômico, p. 211.

xxvi ARAÚJO JÚNIOR, João Marcello de. Os crimes contra o sistema financeiro no esboço de nova parte especial do código penal de 1994. RBCC, p. 150.

xxvii SANTOS, Cláudia Cruz. O crime de colarinho branco, a (des)igualdade e o problema dos modelos de controlo. Temas de Direito Penal Econômico, p. 211-212.

xxviii SANTOS, Cláudia Cruz. O crime de colarinho branco, a (des)igualdade e o problema dos modelos de controlo. Temas de Direito Penal Econômico, p. 213.

${ }^{\text {xxix }}$ DIAS, Jorge de Figueiredo e ANDRADE, Manuel da Costa. Problemática das infracções contra a economia nacional. Direito Penal Económico e Europeu: textos doutrinários, v. I, p. 320.
} 
${ }^{\mathrm{xxx}}$ DIAS, Jorge de Figueiredo e ANDRADE, Manuel da Costa. Criminologia - o homem delinquente e a sociedade criminógena, p. 448.

xxxi SANTOS, Cláudia Cruz. O crime de colarinho branco, a (des)igualdade e o problema dos modelos de controlo. Temas de Direito Penal Econômico, p. 214-215.

xxxii SANTOS, Cláudia Cruz. O crime de colarinho branco, a (des)igualdade e o problema dos modelos de controlo. Temas de Direito Penal Econômico, p. 219-220.

xxxiii Algumas soluções apresentadas de qual será a melhor maneira de reagir à criminalidade de colarinho branco podem ser verificadas no artigo de NUÑEZ FERNANDES, José. Algunos aspectos conceptuales y políticos de la criminalidad de cuello blanco. Cuadernos de Política Criminal, Madrid: Instituto Universitario de Criminología, $\mathrm{n}^{\mathrm{o}}$ 71, 2000, p. 531-534. E, ainda, quanto ao cabimento das sanções ao criminoso de colarinho branco, FELDENS, Luciano. Tutela penal de interesses difusos e crimes do colarinho branco, p. 228 e ss e NETTUNO, Antonio e LADINA, Andrea. Le richieste ed bisogni di sostegno psicologico dei cosiddetti 'tangentisti' ristretti nell'instituzione totale. Rassegna Italiana di Criminologia, Milão: Giuffrè Editore, INDICI 1994, p. 561-562.

${ }^{\text {xxxiv }}$ DIAS, Jorge de Figueiredo e ANDRADE, Manuel da Costa. Criminologia - o homem delinquente e a sociedade criminógena, p. 375.

${ }^{x x x v}$ DIAS, Jorge de Figueiredo e ANDRADE, Manuel da Costa. Criminologia - o homem delinquente e a sociedade criminógena, p. 376.

xxxvi “(...) Mais recentemente, surgiram novas figuras delitivas como, por exemplo, grandes estelionatos, falsidades ideológicas, crimes contra as relações de consumo, monopólios irregulares, os escândalos financeiros e mesmo as grandes falências, com prejuízos incalculáveis. É inegável que para a prevenção e repressão de infracções desta natureza se justifica a utilização de graves sanções, inclusive privativas de liberdade." (grifo nosso) Cf. BITENCOURT, Cezar Roberto apud FELDENS, Luciano. Tutela penal dos interesses difusos e crimes do colarinho branco, p. 236.

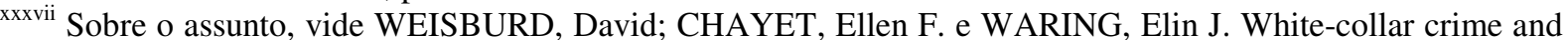
criminal careers: some preliminary findings. Crime \& Delinquency, California: Sage Periodicals Press, v. 36, $\mathrm{n}^{\circ}$ 3 , july 1990, p. 342-355. Os autores afirmam, expressamente, na página 352 da obra citada, em suas conclusões, a reincidência da prática de ilícitos pelos white-collar criminals: “(...) white-collar criminals are often repeat offenders".

xxxviii COSTA, José de Faria e ANDRADE, Manuel da Costa. Sobre a concepção e os princípios do direito penal económico - notas a propósito do colóquio preparatório da AIDP. Direito Penal Económico e Europeu: textos doutrinários, v. I, p. 360.

${ }^{\text {xxxix }}$ Sobre o assunto, vide RODRIGUES, Anabela Miranda. Contributo para a fundamentação de um discurso punitivo em matéria fiscal penal. Direito Penal Económico e Europeu: textos doutrinários, Coimbra: Coimbra Editora, v. II - problemas especiais, 1999, p. 484-485.

${ }^{\mathrm{xl}}$ ALBERGARIA, Pedro Soares de. A posição de garante dos dirigentes no âmbito da criminalidade de empresa, RPCC, p. 609-610 